\title{
Exploring the dynamics of food routines: a practice- based study to understand households' daily life
}

\author{
Margot Dyen ${ }^{\mathrm{a}}$, Lucie Sirieix ${ }^{\mathrm{a}}$, Sandrine Costa ${ }^{\mathrm{b}}$ \\ Laurence Depezay ${ }^{c}$, Eloïse Castagna ${ }^{c}$ \\ ${ }^{a}$ MOISA, Montpellier SupAgro, CIHEAM-IAMM, CIRAD, INRA, Univ Montpellier, Montpellier, France \\ ${ }^{\mathrm{b}}$ MOISA, INRA, CIHEAM-IAMM, CIRAD, Montpellier SupAgro, Univ Montpellier, Montpellier, France \\ ${ }^{c}$ Fondation Louis Bonduelle, Villeneuve d'Ascq, France
}

\begin{abstract}
Purpose: This paper aims to explore consumers' experienced life and studies how practices interconnect and are organized on a daily basis. The objective is to contribute to a better understanding of how (or whether) it is possible to interfere with daily practices, as public policies pretend to do, to address several societal challenges (food waste, healthy eating, greenhouse gas reduction, social equity, etc.).
\end{abstract}

Design/methodology/approach: Using the concepts of routine, ritual and practice to understand the dynamics of daily life from a practice theories perspective, this study is based on a qualitative methodology combining a projective method of collage coupled with semi-structured interviews with 23 participants and, participant observation of shopping, cooking and mealtimes at home with 11 of the 23 participants.

Findings: Results show that the degree of systematization of practices defines different types of routine according to various systematization factors, suggesting a distinction between systematized, hybrid and partially systematized routines. Beyond the question of the degree of systematization of practices composing routines, results show that some practices are embedded in daily routines due to their ritualization.

Research limitations/implications: This work takes part of the debates on how to study households' daily life, and challenges the understanding of daily life activity more globally than just by the prism of isolated actions. For that, this study uses the concepts of routines and rituals. They are relevant to describe and to capture the tangle of practices composing food activities. The study shows that the material dimensions, the pressure of time, the commitments and the social relations condition the global arrangement of the food practices in a variable way.

Practical implications: Such results offer new perspectives for intervening on households' daily consumption by understanding the global dynamics of food routines.

Originality/value: This work contributes to a better understanding of consumers' food practices and routines and to a practice-change perspective considering constrained and routinely constructed lives.

Keywords: Consumer, Ritual, Routines, Food practices

Paper type: Research paper 


\section{Introduction}

The daily lives of consumers are at the center of many attentions and numerous studies seek to understand the dynamics that organize the time and tasks of the members of a household. Food is, because of its complexity and essentiality to life, a privileged subject for studying the dynamics of daily actions and relationships between individuals (Warde 1994). Studies on the organization of family life usually center their questions on specific stages of the family life. For example, in the case of food, the literature focuses on parent / child relationships when eating (Dixon and Banwell, 2004), rituals during daily family meals (e.g. Fese, 2006) or the division of labor (e.g. Schwanen et al., 2007). This rich literature makes it possible to understand how practices, during a given activity (e.g. stocking, cooking), concentrate multiple issues and become identity of the home and, a fortiori, of the family (Epp, 2008). Previous marketing studies have sought to model behaviors within the family, showing, for example, how children's consumption behaviors depend on normative social factors (influence of parents, peers), factors related to the environment (advertising) and attitudinal factors (Tarabashkina et al., 2017). Other work completes the analysis of these factors, highlighting for example potential conflicts between the preferences of members of a household or a family (Olsen and Grunert, 2010). For their part, by adopting a more qualitative approach to eating behaviors, Furst et al. (2000) describe the interweaving of personal, social and cultural criteria for food product choices. These authors then show that, depending on the situation, individuals favor these criteria in a different way, and this in particular according to the composition of the households (e.g. with or without children). This refers to the role of "gatekeeper" endorsed by some members of the family (Burton et al 2017). Thus, these different approaches show that parameters of different kinds are necessary for the analysis of the everyday life of families. In parallel with this, studies examine the temporality of practices in a broader way, notably asking the question of the distribution of time between different activities (Shove, 2009; Southerton et al., 2012). This literature makes it possible to study the factors underlying the temporal organization of daily life, notably asking the question of the material dimensions, and shows for example that the distance to the stores (e.g. Hino, 2014) or the possession of household appliances (e.g. Truninger, 2011) play a role in the orchestration of everyday life.

Existing work is therefore fueling interventions on consumption since it helps to know how to intervene at the level of a type of practice (e.g. eating, buying, cooking). However, this literature does not generally take into account the organization, among themselves, of 
practices contributing to food such as supply, preparation, consumption, storage or even waste. This is why this study proposes an analysis of the dynamics of the food routines. This work is part of a broader project that aims to understand how food practices interconnect practices associated with food waste and practices associated with healthy eating. In this, this work responds to the project to better understand the food practices of households and families, because ensuring a healthy diet while managing the economy of the home is at the heart of the issues faced by consumers and responsible for households (Evans, 2011; Cappellini and Parsons, 2012). Hence, this study aims to answer the following questions: how are the food practices of a household interconnected and organized into routinized and ritualized sets? What are the factors impacting the degree of systematization of practices and therefore the dynamics of routines? To answer these questions, this study adopts the framework of the theories of practice and is based on a qualitative study.

\section{Theoretical framework}

This work aims to describe daily activities, to understand how they are organized in view of the temporal and material dimensions that constrain them and how interactions between family members influence this organization of activities. The following section shows that the theories of practice provide a relevant framework for such goals, with the concepts of routines and rituals.

\subsection{Theories of practice, a relevant framework for understanding "how families live their lives"}

Practice theories advocate for an alternative approach to consumer studies which is not based on consumers' rationality but focuses on practices rather than on individuals (Halkier and Jensen, 2011). They consider them as practice-makers rather than decision-makers. This stream considers the context of daily routine and how individuals co-construct practices by performing them (Evans et al., 2012, Warde, 2005). Practice theories analyze the "elements" that constitute practices (Hargreaves, 2011, Shove et al., 2012) and, how practices are interconnected (Warde, 2005). Schatzki (2005), who describes practices as a set of actions, invites to study the arrangements of actions in their spatio-temporal dimensions, which responds to the specificity of domestic life, consisting of a set of coordinated actions that form what can be called the daily routine of consumers (Wahlen, 2011). How to apprehend these connected actions? According to Shove, "elements" (material, meaning and competences) explain how practices interconnect and, if two practices share a common element, they partly Marketing, Online First. , DOI : 10.1108/EJM-10-2017-0775 
share the same dynamic (Shove et al., 2012). Approaches vary to deal with the links between practices and, even the definition of what is a practice is debated among the theorists (Hargreaves, 2011). The most employed definition, which is adopted in this study, is Reckwitz's one, describing practice as « a whole and stabilized « configuration » consisting of several elements, interconnected to one another : forms of bodily activities, forms of mental activities, «things » and their use, a background knowledge in the forms of understanding, know-how, states of emotion and emotional knowledge » (Reckwitz, 2002).

Thus, the theories of practice allow an analysis of daily activities interconnected with each other taking into account their material, social and temporal dimensions. This allows for new approaches to transition to more sustainable practices (eg Sargant, 2014), which corresponds to the objective of this article. More specifically, the concepts of routines and rituals as defined in the framework of the theories of practice offer a conceptual framework adapted to this study.

\subsection{Conceptual Framework: routines and rituals for analyzing daily dynamics}

\subsubsection{A practice-based definition of routines}

For a large part of the scientific community studying consumer action, routines are "unthinking" acts (Warde, 2016). However, more than a cognitive phenomenon underlying the loss of consciousness of (daily) actions, they are mostly an arrangement of practices. According to Warde, practice theories partly agree with the cognitive perception for which routines are defined as an unthinking act, but the nuance is rather to consider routines as a lack of deliberation. This is in agreement with the idea that routines allow a cognitive discharge because the response is somehow pre-established and optimal for a given context. The main difference is then to focus on the description of material, socio-technical and normative dimensions of the social arrangements resulting in routinized consumption (Magaudda 2011, Truninger, 2011). In order to understand the daily dynamics and, added to the concept of routine that allows to analyze the organization in sequence, the concept of ritual makes it possible to understand the anchoring of certain practices according to their meaning for the carriers of practices.

\subsubsection{Rituals, analytical objects of symbolic actions}

The following subsection deals with the ritualized dimension of certain daily activities and shows that rituals may help reaffirm or actualize values and/or manage moral disorders coming from societal disruption. 
Rivière (1996) emphasizes that rituals are in fact the ritualization of beliefs. For Otnes and Lowrey (2004), "rituals are a way of organizing and assimilating experience, relying on tacit norms and values, thus binding individuals to each other." Thus, rituals are means of reactivating symbolic values through mundane actions. This need for actualization of one's value may come from a need to maintain individual moral order (Goffman 1968, in Holt, 1992). Indeed, just as religious rites are means of preserving certain values to handle the evolution on societal values, everyday life rituals can be considered as means of managing ontological disorders. Ritualized moments are preserved to maintain a minimum level of control and orientation of one's acts (Ger and Kravetz, 2009). This partly explains why ritualized actions are organized in a given time, and the moments in which these rituals are expressed are more compartmentalized: they are dedicated moments, identifiable times and do not necessarily echo the usual observed routines of consumption (Warde, 2016). In this study, rituals are thus defined as habits carrying a particular symbolism, shared on varying scales (individual, in the family, between friends,...) and it is the repetition of the performance that proceeds to the ritualization of a form of protocol. In order to contribute to the understanding of household eating habits, this study relies on the concepts of routines and rituals to understand how the food practices of a home are arranged in routinized and ritualized sets.

\section{Material and method}

This work aims at understanding processes and at exploring how daily consumption is organized. In this perspective, a qualitative approach is relevant. The two challenges associated to the data collection are 1) the comprehensiveness of the described practices and 2) the precision with which they are presented. They lead to choose a two-step methodology based on projective method of collage coupled with interviews and participant observation of shopping, cooking, and eating practices. Semi-directive interviews coupled with projective method of collage are relevant to invite people to think about their own experience, as they offer a place for introspection before discussing with the interviewer. Projective methods are effective to re-center people on their preoccupations and representations (Valette-Florence and de Barnier, 2009). Such an approach can seem contradictory with a practice-based study as it focuses on people's representations of their own experience, and not only on actual practices. However, even if it is filtered through their prism, people depict their daily lives with comprehensiveness, which is essential according to the objective of describing food practices. Moreover, participant observations complete this data collection, allowing to articulate a rather exhaustive collection of declared practices with an observation of real Marketing, Online First. , DOI : 10.1108/EJM-10-2017-0775 
context. Indeed, observations complement the data collection with an insight of people's material environment, of interactions with other members of the household, and of bodily activities and the associated know-how. To conclude, this methodology aims to describe the whole nexus of food practices with a qualitative approach combining a declarative projective method to describe the practices and observations to understand the enacted and materialized practices. It allows answering Rook's call: “to study consumers' ritual actions challenges the research community to try more holistic, qualitative approaches. By its very nature much ritual action invites field observation. To extract the meanings imbedded in ritualized action may require intensive and open-ended interviewing. And in some cases, consumers may not have a conscious understanding of or direct access to a ritual's meanings; indirect approaches such as projective techniques may prove useful" (Rook, 1985). This study applies Rook's recommendation not only to the study of rituals but more broadly to that of routines.

This study was conducted in France as part of a larger project on food waste and healthy eating. Thus, the sample was developed in order to generate as much variability as possible in the practices related to these two themes: varied age, socio-professional category, household's size, hobbies (used as an approximation of a part of their interests). Such a sample is adapted to the objectives of this study because it guarantees the presence of varied food practices in terms of product management (link with waste) and relation to food (link with nutritional considerations). The interviewees were always at least partially in charge of feeding the household, i.e. they were shopping or cooking regularly. The sample is composed of 23 participants. 
Table 1 : Description of the sample.

\begin{tabular}{|c|c|c|c|c|}
\hline Coded name & Sex & $\begin{array}{c}\text { Socio- } \\
\text { profesional } \\
\text { category } \\
\end{array}$ & $\begin{array}{l}\text { Members of the } \\
\text { household }\end{array}$ & Age \\
\hline Musician & $\mathrm{F}$ & + & Partner & 33 \\
\hline Regulated & $\mathrm{F}$ & Retired & Alone & 67 \\
\hline Climber & $\mathrm{F}$ & - & Partner & 29 \\
\hline Carnivore & $\mathrm{F}$ & + & $\begin{array}{l}\text { Husbands and two } \\
\text { children }\end{array}$ & 48 \\
\hline Father & $\mathrm{H}$ & - & $\begin{array}{l}\text { Wife and two } \\
\text { children }\end{array}$ & 40 \\
\hline Lister & $\mathrm{F}$ & - & Mother & 26 \\
\hline Traditional & $\mathrm{F}$ & + & Alone & 29 \\
\hline Frugal & $\mathrm{H}$ & - & Wife and daughter & 46 \\
\hline Retired & $\mathrm{H}$ & Retired & Alone & 69 \\
\hline Fluidity & $\mathrm{F}$ & - & Husband and son & 33 \\
\hline Impulsive & $\mathrm{F}$ & - & A roomate & 21 \\
\hline Mother & $\mathrm{F}$ & Unemployed & $\begin{array}{c}\text { Daughter } \\
\text { (alternating } \\
\text { custody) }\end{array}$ & 42 \\
\hline Enduring & $\mathrm{F}$ & - & Mother & 48 \\
\hline Foreigner & $\mathrm{F}$ & - & Husband and son & 42 \\
\hline Thinker & $\mathrm{F}$ & Student & Alone & 30 \\
\hline Claimer & $\mathrm{H}$ & - & Two roomates & 24 \\
\hline Rediscover & $\mathrm{F}$ & Student & Alone & 23 \\
\hline Simple & $\mathrm{H}$ & + & $\begin{array}{c}\text { Alone, sometimes } \\
\text { with his son }\end{array}$ & 52 \\
\hline Constraint & $\mathrm{F}$ & - & $\begin{array}{c}\text { Husband and two } \\
\text { daughter }\end{array}$ & 30 \\
\hline Sportful & $\mathrm{H}$ & + & Partner & 32 \\
\hline Researcher & $\mathrm{F}$ & + & Husband and child & 32 \\
\hline Invested & $\mathrm{H}$ & + & Partner & 29 \\
\hline Curious & $\mathrm{H}$ & + & $\begin{array}{l}\text { Wife and two } \\
\text { children }\end{array}$ & 37 \\
\hline
\end{tabular}

Names have been coded to ensure confidentiality.

Codes are based on one or on several characteristics of participants' food practices.

In grey, the 11 participants who agreed to participate in the two steps (collages and observation, see the next sections)

\subsection{Projective method of collage coupled with individual semi-directive interviews}

People received the following instructions for the collage:

"Realize a poster representing your food practices: from shopping to eating practices, and represent what constrains your organization" 
Participants disposed of magazines (women's, decoration, multimedia, agricultural world, travel) and drawing material. Collages in themselves lasted 40 minutes in average, and interviews lasted $1 \mathrm{~h} 15 \mathrm{~min}$ in average. Interviews have been fully transcribed. Collages were very useful tools for the interviewer, as they give a kind of interview guide and a source of data. This really helps to lead the interview as it permits to refer to individuals 'own structuration of ideas.

Projective methods are generally used for bias reduction, the study of individual perceptions (Cottet et al., 2008) or collective ones (Havlena and Holak, 1996), and for access to unconscious processes (Gomez and Cuynet, 2011) or mental images among consumers (Valette-Florence and de Barnier, 2009). In this study, this technique is used for its role of facilitator of dialogue to allow individuals to remember (Rook, 2006) and to represent their daily lives. Thanks to the resulting exchanges, this technique allows to observe (through the discourse) what happens in the performance of the practice (Hargreaves, 2011).

\subsection{Observation in situ of shopping, cooking and eating practices}

One year after the collages, participant observations of shopping, cooking and eating-at-home practices give information about participants' material environment, about enacted know-how and about interactions among the household. It is also an opportunity to make a new wave of interviews. Observations and interviews lasted one hour in average for the shopping practices and 2 hours in average for the cooking and eating-at-home practices. These interviews allow checking if special practices maintain even if life has changed. 11 of the 23 participants recruited for the collages/interviews agreed to participate in this step of the methodology, which was potentially more intrusive and more constraining.

\section{Findings}

The results show that food routines are organized from the elements that make up the practices. This leads to a typology of three types of routines:

- Those mainly composed of systematic practices because of the pressure of time or particular commitments, including the ritualization of certain practices, for which a particular anchoring and dynamics are observed.

- Those mainly composed of occasional practices according to the social relations inherent to the practices 
- Hybrid routines combining occasional practices and systematic practices, either in terms of time (periods when practices are systematic and periods when practices are occasional) or according to the categories of practices involved (eg shopping practices systematic but predominantly occasional consumption practices) and in terms of material or organizational elements.

In order to understand this typology and to answer the research question related to the arrangement of routinized and ritualized sets, the following sections present the role played by the different categories of elements in the degree of systematization of practices and in the dynamics of routines, as well as the role of the social and material environment in structuring routines.

\subsection{Time pressure, a factor influencing the systematization of practices}

Results show that for some participants, systematized practices emerge as an answer for time management. This is the case of Curious, whose life is under time constraints. He explains:

"The constraint here is to be able between $6 \mathrm{pm}$ and $7.30 \mathrm{pm}$ to pick up the children, do the homework with one of the two, take a shower and prepare the meal $[\ldots]$ so what works quite well for now is that I arrive at my son's school at 6 , at 6.10 we are at home (so 5 or 10 minutes later), after what we have 20 minutes to do the homework, and at 6.20 I go pick up my daughter at nanny's place, at 6.30 I'm back [lough] and between 6.30 and 7.30 either we finish the homework if it's difficult or, yesterday night for example, I showed him some calligraphic technics".

Curious always has one hour for all these activities on the evening, so cooking practices are the same to optimize the time management. It is the case for all his practices: for lunchtime, he is also under pressure since he goes to the swimming pool. This does not mean that he does not take time to eat, but the sequence is under the pressure of the consecutive actions of his life. On the morning too, the systematized practices are structured by the constraints of the flow of time.

Mother's practices also illustrate this idea as she is separated and her practices differ between the weeks she is in charge of her daughter and the weeks she is not. In this last case, she eats with her boyfriend. During the first type of week, she focuses on time management, so just as for Curious, more systematized practices with her daughter and more impulsive, variable and non-systematized practices with her boyfriend can be observed. 
This section contributed to understand the constraints experienced by practices carriers. In the case of Curious, sequences of practices are adapted to and structure the flow of time, and in the case of Mother, the systematization of practices varies over time according to the temporal pressure to which she is subjected.

\subsection{Commitments as a guideline for systematizing practices within routines}

Lister's practices appear in a very systematized way as it is the way she controls her food intake in a diet perspective. She constructs her shopping list always the same way (that does not mean that the list is always the same), she goes for shopping on the same day as there are promotions on Thursdays, and she always cooks on the same days:

«So this is the Thursday of week 1 and this is the Thursday of week 2 , so in general I've done shopping on the first Thursday, and I've cooked on the first Saturday. So here you have a second week end, so this is the week 0 , you see, because from Thursday to Saturday there are two days [before I cook] so the shopping is enough as I almost always buy a pre-prepared meal, ready in 30 seconds for the end of the week".

Lister gets organized this way to control her diet, as for her, cooking in advance is the only way she eats homemade (so healthier) food. Based on this purpose, a lot of organizational aspects adapting or depending on the infrastructural environment optimize this organization (food recipes reviews, a pool of plastic boxes to stock, etc.).

Just as Lister, Regulated's practices are systematized in a weight reduction perspective. She explains:

"yeah, [when you try to lose weight] the most important thing is to be regular, and never to skip a meal".

In this way, Lister and Regulated's practices are systematized to limit temptation and to reassure that this routine is approved.

These examples illustrate how specific purposes can lead to a systematization of practices in order to control them. This can also result in a special practice, as Lister explains below:

"There are days when we don't want to eat healthy food... we call it «Junk Food Day », we have one every week"

So here, Lister explains that this practice is a kind of break in her efforts not to eat unhealthy food. This practice of preserving a «junk food day » can be identified as a ritual, since 
ritualized moments are preserved islands to maintain a minimum level of control and orientation of one's acts (Ger and Kravetz, 2009).

Added to the commitments as purposes, the results show that the practices can be guided by commitments illustrating the values of the carriers of practices: Climber's shopping practices are always the same, even if she could simplify: she shops every two weeks in an organic supermarket. In addition, she buys fruits and vegetables every week directly from a producer, even the weeks she goes to the supermarket where she could buy all her vegetables. Here, a highly systematized practice appears, which seems to go beyond the utilitarian dimension of shopping, as it seems impossible for her to substitute the practice.

On the contrary, Frugal's case exemplifies how a lack of special involvement in food can lead to a highly systematized routine: Frugal eats only one meal per day, for dinner. This is an inherited habit of his former working period. Therefore, for him, food consumption is always the same. Concerning shopping practices, Frugal and his family go every week to the same supermarket, and even if products vary, the decision process and the practice's characteristics (time spent, task repartition, amount of food) are similar from one week to another.

Added to the role played by the different categories of elements in the degree of systematization of practices and in the dynamics of routines, the social and material environments play a role in structuring routines.

\subsection{Social relations framing food practices at the heart of structuring routines}

Food is usually a social activity, especially in France where meals are usually taken together, and social relations structure food routines with rituals of meetings around meals. Similarly, peers play a role in the systematization of practices, sometimes being a source of impulsiveness. The lack of social relations around food may, on the contrary, have the opposite effect with mainly occasional food practices due to lack of structuring.

One example of typical ritualization is Musician's practice of inviting her friends to eat a special dish, the traditional autumnal pumpkin:

«Sometimes I do invite plenty of my friends to eat the pumpkin [...] my mother did that; it is a kind of ritual »

The same kind of ritual rhythms Lister's practices as she meets with her mother and grandmother every Sunday to eat "real and good lunch", the definition of "real" coming from the presence of a dessert. In these two situations, the special value relates to sharing, and taking 
care of the family's members the respondents care of, just as Carnivore who goes to the marketplace every Saturday morning with her old mother:

"I go to the market with her because... well, with my job I don't have time for her, because, yes, I would like to have more time to visit her, to spend time, but I don't..."

This is, for her, a way to take care of her family, and she especially underlines the "generational solidarity" around this practice. She maintains it as long as she can, and it primes over any other activity.

Experiencing novelties with others is something common around food. Indeed, when going to the restaurant or to any product tasting, this is the feeling of a special experience, which links people. Results show that some participants organize this experience. Discovery mainly concerns cooking practices, but people experience it while cooking and eating together. For example, Traditional experiences a ritual around discovery:

"yes it's kind of regular, we make quite a lot of these meals with my friend Pierre, in fact we have a kind of game called "world food", we cook something we don't know from abroad $[\ldots]$ and we try to make it every two weeks".

The practice here is organized around the cooking practices. It is oriented towards foreign dishes, but the important purpose remains the shared moment around food.

On the contrary, Retired acts without rules because of a reduced family and social life around food: he almost never shares meals, making that his consumption is anarchic, alternating between "normal rhythm of mealtimes" and eating whenever he feels hungry without any attention to healthy eating. Food provisioning practices follow this dynamic, and he can shop either every 10 days or every day depending on his wish to anticipate. Retired underlines himself that being alone contributes to this rhythm:

"Eating bothers me. So the quicker the better, because I think that when we eat we need to be two [..]. Alone, lots of desires disappear."

In this way, the driving force of food practices here is not directly related to food in itself.

\subsection{The material environment, an element influencing the flexibility of routines}

Musician's consumption practices are always the same, the conditions under which they are realized repeating themselves day after day. This reveals a systematization of her consumption practices, which are in accordance with her hunger's rhythm, as she prefers 
eating a consistent meal rather than snacking. This results in a very structured sequence of consumption practices. On the contrary, she goes shopping differently, without any rules neither for the moments she goes nor for the place (market, supermarket, convenience shops, etc.). She buys products depending on logistical aspects related to her very flexible job. The even more predominant element contributing to this non-systematization of her practices is the fact that she lives in a city center, so a lot of little shops are available around her house. This shows how infrastructures contribute to the construction of a sequence of practices.

In sum, the elements of practice are not only the origin of the practices as constitutive elements, but they are also binders that coordinate the sets that are the routines.

\section{Discussion}

This work contributes to a conception of food consumption not as isolated actions but as a function of the temporal order within which the dynamics of routines rest on various constitutive elements of practices rather than solely on questions of will and choice. This makes echo to Warde's (2016) result that food practice is a compound practice made of several others dispersed in time and space.

The analysis of the influence of social relations on routines makes echo to the idea of social time (Southerton et al., 2012), which means that time is defined, in fact, by the social. The coordination of individuals over time is part of the socialization and therefore rhythms activities. This is particularly evident in the fact that among family members, the management of temporality is transmitted and shared within households (Morgenstern et al., 2015). It is even characteristic of it.

In addition, the results highlight that time can also be thought of as a resource, an element to optimize. This is apparent from the case of Curious, who optimizes the time to achieve a set of tasks in a time he has delimited. This temporal resource can sometimes be oriented towards preserving sets such as rituals and certain systematic practices. This makes echo to the work of Hogg et al. (2003), who use the term "time oasis" to describe family meals. Southerton (2003) provides interesting insights on these results by emphasizing that the adoption of very rigid routines and sometimes very detailed organizational supports (technologies, diaries, etc.) respond to the stress of the 24-hour society observed today (ie the possibility to be constantly connected, to be able to shop on wider and wider time slots, etc.). This suggests that synchronizing individuals around food activities may be a response to this stress. However, keeping a niche in one's schedule for an activity is nothing without access to a dedicated 
place. This is why the question of time is associated with the question of the spaces in which practices are performed (Southerton et al., 2012). The results of this work have highlighted the material and infrastructural support necessary for different food practices, as well as the structuring power of certain infrastructures on the routines (such as the supply practices of Musician backed by the infrastructure of living in downtown). In this way, it is verified that the temporal experience is intricate with the material facilities, the commitments and the social dimension of the food activities.

This work therefore analyzes consumption as subject to relations between the constitutive elements of the practices. One of the contributions of this study is to not only identify or analyze these elements but to show that some may be more important than others according to the practices. It is then possible to evoke a form of hierarchy of elements according to the practices: for example, some practices are more anchored in the routines because of their meaning while others are more anchored because of the material environment on which they depend. This helps to deepen the analysis of the constitutive elements as defined by Hargreaves (2011) and Shove et al. (2012) by showing that the elements themselves are subject to dynamics. Also, the results of this study contribute to seeing how the elements are responsible, in addition to the implementation of the practices (Sargant, 2014), of their orchestration in routines.

Finally, this work shows that routines allow the spatio-temporal meeting of groups of individuals, while providing a form of security for the fulfillment of commitments (Warde, 2016). Indeed, the routines are also arrangements supported by the commitments of the carriers of practices. It is in this that the study of rituals can be linked to the study of routines, which are essentially reserved or preserved moments contributing to the balance and the control of the carriers of practices on their acts (Ger and Kravetz, 2009 ). Practices can then be particularly rooted in the routines according to the purposes associated with them. These purposes may foster relations between peers and/or allow a control over certain practices. Woermann and Rokka (2015) argue that the experience of temporality can be an effect of the concordance of the elements. In this, this study contributes to new data for the development of public policies, the role of which could be to guarantee or favor the missing elements so that the arrangement of the temporality corresponds to the implementation of recommended practices. Warde and Welch (2015) argue that the temporal coordination of practices is an opportunity for interventions aimed at changing consumer behavior. More, understanding 
how the daily activities are coordinated, potentially contributes to see how practices can be the site of social change (Keller et al., 2015).

\section{Conclusion}

This work takes part of the debates on how to study households' daily life, and challenges the understanding of daily life activity more globally than just by the prism of isolated actions. For that, this study uses the concepts of routines and rituals. They are relevant to describe and to capture the tangle of practices composing food activities. Routines are a challenging object of study, and this works contributes to their analysis thanks to a two-step qualitative methodology to capture the variability and the interconnection of practices (thanks to collages) and a way of perceiving a part of the social, material, and embodied aspects of practices composing routines (from participant observation). This study makes it possible to report on the dynamics of the daily practices of the home according to their systematization. Results reveal a 3-types classification of routines: 1) one mostly composed of systematized practices; 2) one mostly composed of occasional practices; and 3) a hybrid one, interconnecting occasional and systematized routines. These different forms of routines can be explained from the constitutive elements of the practices. The study shows that the material dimensions, the pressure of time, the commitments and the social relations condition the global arrangement of the food practices in a variable way. Such results offer new perspectives for intervening on households' daily consumption by understanding the global dynamics of food routines.

However, this study is not exempt from limits, and the main one is a methodological one. More observations would deepen the observation of other constitutive elements of practices and eventually lead to new findings on how the practices are cemented, apart from motivational reasons. Another challenge faced is the definition of practice. It is a well-known challenge for researchers working with practice theories (Keller et al., 2015), and it is a perspective for future work to deepen the question of how to define such a complex practice as food consumption. This study contributes to this enterprise, but work remains to be done. 


\section{References}

Burton M, Reid M, Worsley A, et al. (2017) Food skills confidence and household gatekeepers' dietary practices. Appetite 108: 183-190.

Cappellini B and Parsons E (2012) Practising thrift at dinnertime: Mealtime leftovers, sacrifice and family membership. The Sociological Review 60(S2): 121-134.

Cottet P, Ferrandi J-M and Lichtlé M-C (2008) Les dimensions de la résistance à la publicité Une approche qualitative par la méthode des collages. In: Journées de recherches en marketing de Bourgogne.

Dixon J and Banwell C (2004) Heading the table: parenting and the junior consumer. British Food Journal 106(3): 182-193.

Epp AM and Price LL (2008) Family identity: A framework of identity interplay in consumption practices. Journal of Consumer Research 35(1): 50-70.

Evans D (2011) Beyond the throwaway society: ordinary domestic practice and a sociological approach to household food waste. Sociology 46(1): 41-56.

Evans D, McMeekin A and Southerton D (2012) Sustainable consumption, behaviour change policies and theories of practice. In: The habits of consumption, Helsinki.

Fiese BH, Foley KP and Spagnola M (2006) Routine and ritual elements in family mealtimes: Contexts for child well-being and family identity. New directions for child and adolescent development 2006(111): 67-89.

Furst T, Connors M, Sobal J, et al. (2000) Food classifications: Levels and categories. Ecology of food and nutrition 39(5): 331-355.

Ger G and Kravetz O (2009) Special and ordinary time. Tea in motion. In: Time, consumption and everyday life: practice, materiality and culture, Berg, pp. 189-202.

Gomez V and Cuynet P (2011) L'image du corps chez l'adolescente obèse. Perspectives Psy 50(2): 117-127.

Halkier B and Jensen I (2011) Methodological challenges in using practice theory in consumption research. Examples from a study on handling nutritional contestations of food consumption. Journal of Consumer Culture 11(1): 101-123.

Hargreaves T (2011) Practice-ing behaviour change: Applying social practice theory to proenvironmental behaviour change. Journal of Consumer Culture 11(1): 79-99.

Havlena WJ and Holak SL (1996) Exploring nostalgia imagery through the use of consumer collages. Advances in consumer research 23: 35-42.

Hino H (2014) Shopping at different food retail formats: Understanding cross-shopping behavior through retail format selective use patterns. European Journal of Marketing 48(3/4): 674-698. 
Hogg MK, Maclaran P and Curasi CF (2003) Consumption, role transitions and the reconstruction of the self: an exploratory study of social capital within the context of transitional consumers. ACR European Advances 19: 258-262.

Holt DB (1992) Examining the Descriptive Value of" Ritual" in Consumer Behavior: View From the Field. Advances in Consumer Research 19(1): 213-218.

Keller M, Kiisel M and Vihalemm T (2015) From Intervention to Social Change: a guide to reshaping everyday practices. Ashgate Publishing, Ltd.

Magaudda P (2011) When materiality 'bites back': Digital music consumption practices in the age of dematerialization. Journal of Consumer Culture 11(1): 15-36.

Morgenstern A, Debras C, Beaupoil-Hourdel P, et al. (2015) L'art de l'artichaut et autres rituels: transmission de pratiques sociales et alimentaires dans les diners familiaux parisiens. Anthropology of food (9).

Otnes CC and Lowrey TM (2004) Contemporary consumption rituals: A research anthology. Taylor \& Francis.

Ottar Olsen S and Grunert KG (2010) The role of satisfaction, norms and conflict in families' eating behaviour. European Journal of Marketing 44(7/8): 1165-1181.

Reckwitz A (2002) Toward a Theory of Social Practices A development in culturalist theorizing. European journal of social theory 5(2): 243-263.

Rivière C (1996) Pour une théorie du quotidien ritualisé: et présentation des contributions. Ethnologie française 26(2): 229-238.

Rook DW (1984) Ritual behavior and consumer symbolism. NA-Advances in Consumer Research 11: 299-284.

Rook DW (2006) Let's pretend: projective methods reconsidered. Handbook of qualitative research methods in marketing (Part II).

Sargant EM (2014) Sustainable food consumption: a practice based approach. Wageningen University, $\mathrm{PhD}$ Dissertation

Schatzki TR (2005) Practice mind-ed orders. The practice turn in contemporary theory 11.

Schwanen T, Ettema D and Timmermans H (2007) If you pick up the children, I'll do the groceries: spatial differences in between-partner interactions in out-of-home household activities. Environment and Planning A 39(11): 2754-2773.

Shove E (2009) Everyday practice and the production and consumption of time. In: Time, consumption and everyday life: practice, materiality and culture, Berg, pp. 17-33.

Shove E, Pantzar M and Watson M (2012) The dynamics of social practice: everyday life and how it changes. Sage Publications.

Southerton D (2003) Squeezing Time' Allocating Practices, Coordinating Networks and Scheduling Society. Time \& Society 12(1): 5-25. 
Southerton D, Diaz-Méndez C and Warde A (2012) Behavioural Change and the Temporal Ordering of Eating Practices: A UK-Spain Comparison. International Journal of Sociology of Agriculture \& Food 19(1).

Tarabashkina L, Quester PG and Crouch R (2017) Children and energy-dense foods-parents, peers, acceptability or advertising? European Journal of Marketing 51(9/10): 16691694.

Truninger M (2011) Cooking with Bimby in a moment of recruitment: Exploring conventions and practice perspectives. Journal of Consumer Culture 11(1): 37-59.

Valette-Florence R and de Barnier V (2009) Les lecteurs sont-ils capables d'anthropomorphiser leur magazine? Management \& avenir (7): 54-72.

Wahlen S (2011) The routinely forgotten routine character of domestic practices. International Journal of Consumer Studies 35(5): 507-513.

Warde A (2005) Consumption and theories of practice. Journal of consumer culture 5(2): $131-153$.

Warde A (2016) The Practice of Eating. Cambridge: John Wiley \& Sons.

Warde A and Hetherington K (1994) English households and routine food practices: a research note. The Sociological Review 42(4): 758-778.

Welch D and Warde A (2015) Theories of practice and sustainable consumption. In: Handbook of research on sustainable consumption, pp. 84-100.

Woermann N and Rokka J (2015) Timeflow: How consumption practices shape consumers' temporal experiences. Journal of Consumer Research 41(6): 1486-1508. 